\title{
The early impact of therapeutic alliance in brief psychodynamic psychotherapy
}

\section{O impacto inicial da aliança terapêutica em psicoterapia psicodinâmica breve}

José Alvaro Marques Marcolino and Eduardo Iacoponi ${ }^{\mathrm{b}}$

${ }^{a}$ Department of Psychiatry and Medical Psychology of the Santa Casa of São Paulo. São Paulo, SP, Brazil. bHealth Services Research Department, Institute of Psychiatry, University of London. London, UK

Abstract Introduction: Therapeutic alliance is a key component of the psychotherapeutic process. This study estimated the impact of the therapeutic alliance as measured by CALPAS-P in an individual brief psychodynamic psychotherapy program.

Methods: To study the impact of the therapeutic alliance patients in psychotherapy answered to the CALPAS$\mathrm{P}$ at the first and third session and to the Self-report Questionnaire (SRQ-20), to the Beck Depression Inventory (BDI) and to the Hamilton Anxiety Scale at the beginning and at the end of psychotherapy.

Results: The study of the impact of the therapeutic alliance in brief psychodynamic psychotherapy showed that higher TUI scores in the first session were significantly associated to the improvement on the BDI. Patients with best scores in the working alliance, measured at the third PWC session had also significant symptomatic changes. Discussion: The study of the impact of the therapeutic alliance in brief psychotherapy indicated that patients who perceived that their therapists had the best capability to understand and to be involved in their issues had best results in reducing depressive symptoms and patients with higher capability to form the working alliance reached the best psychotherapy outcomes.

Keywords Psychotherapy. Psychotherapy brief. Scales. Outcome and process assessment (health care).

Resumo Introdução: A aliança terapêutica é um conceito central do processo psicoterápico. Este estudo avaliou o impacto da aliança terapêutica em um programa de psicoterapia individual psicodinâmica breve.

Método: Para o estudo do impacto da aliança, pacientes em psicoterapia responderam, ao início e ao final de cada psicoterapia, ao Questionário de auto-avaliação (SRQ-20), ao Inventário de Depressão de Beck (BDI) e à Escala de Ansiedade de Hamilton. Responderam também a CALPAS-P ao término da primeira e da terceira sessão.

Resultados: Os resultados mostraram que os pacientes com uma pontuação mais alta da TUI na primeira sessão tiveram um impacto significativo sobre a mudança da sintomatologia medida pela BDI. Foi encontrado ainda que os pacientes com maiores índices de aliança de trabalho, medidos pela PWC na terceira sessão, tiveram um impacto significativo na mudança da sintomatologia medida por todas as escalas.

Discussão: $\mathrm{O}$ estudo do impacto da aliança terapêutica em psicoterapia psicodinâmica breve mostrou que, os pacientes que demonstraram ter percebido seus psicoterapeutas com uma maior capacidade de compreensão e envolvimento em suas questões, tiveram uma maior redução da sintomatologia da depressão e os pacientes com maior capacidade para a aliança de trabalho atingiram os melhores resultados da psicoterapia.

Descritores Psicoterapia. Psicoterapia breve. Escalas. Avaliação de processos e resultados (cuidados de saúde).

This study was performed in the Department of Mental Health of the Brotherhood of Santa Casa de Misericórdia of São Paulo and was based on the doctorate thesis of José Alvaro Marques Marcolino, presented in the Federal University of São Paulo (UNIFESP) in June 7, 2002.

It was supported by a grant from São Paulo Research Foundation (FAPESP - Process n. 99/5517-2)

Received on 9/8/2002. Reviewed on 12/3/2003. Approved on 20/3/2003. 


\section{Introduction}

The need of empirical validations regarding the psychotherapeutic practice has been articulated by several researchers. Commonly, evidence has shown that treated patients have a significant improvement when compared to controls. ${ }^{1-5}$ The several modalities of psychotherapy produce comparable results, despite their different techniques and the distinct theoretical presuppositions about the etiology of psychological dysfunctions. ${ }^{1,4,6-8}$

The biggest gap of these studies was the low attention given to the variables which interfere with the psychotherapeutic process. ${ }^{7}$ In an attempt to find which factors explain the obtained effects and which are common to the different approaches, the research focus has been directed to the role of the patient-psychotherapist relationship, ${ }^{5,9,10}$ which provides the context of all psychotherapeutic processes. ${ }^{11}$

\section{The psychotherapeutic alliance}

Historically, the therapeutic alliance (TA) was the first concept to be developed in order to capture the special role performed by the patient-psychotherapist relationship. In 1912, Freud outlined the first references to this model highlighting its importance as a vehicle for success in psychoanalysis. ${ }^{12}$ Also following a psychoanalytical referential, other authors ${ }^{13,14}$ have reviewed and expanded the concept of TA, and in the last years other theoretical lines ${ }^{15,16}$ also have begun to consider it important.

One of the reasons for the increasing importance of the TA is for its being considered as a common factor to all psychotherapies, as it is not based on a special type of psychotherapeutic technique or on a determined theoretical school. Some authors ${ }^{17}$ have even stated that the TA's quality is more important than the type of psychotherapy in predicting positive therapeutic outcomes. A study which analyzed data from the National Institute of Mental Health - Research Program in the Treatment of Depression found that the TA was responsible for a higher variance in the outcome than the treatment modalities. ${ }^{18}$ Consequently, many current theories which study the process of therapeutic change emphasize the importance of the TA, reaching to a point that some authors have referred to it as a primordial integrative variable of psychotherapies. ${ }^{19}$

\section{Empirical bases of the therapeutical alliance}

Empirical findings have revealed that the TA is one of the few variables in psychotherapy for which there is substantial evidence of a positive impact in the treatment's outcome. ${ }^{20}$ In one study assessing several measures of the alliance and different types of treatment it was observed a significant impact between the TA and psychotherapies outcomes. ${ }^{21}$ Other study ${ }^{22}$ has indicated that, as a rule, the relationship between TA and outcome is moderate and consistent.

Researchers have used several definitions of TA, what has generated multiple assessment instruments. ${ }^{23}$ Although the scales were developed by independent researchers, the measures of the different instruments have shown to be highly correlated..$^{21,22,24-26}$ These researchers have explored the psychodynamic, interpersonal, behavioral and cognitive methods and the patient-centered psychotherapy, ${ }^{27-29}$ showing that the correlation between the alliance and the outcomes seems to be reasonably constant along the several types of treatment, the several clinical diagnoses and the different patient samples. ${ }^{21,22}$

Other significant information is that, most of the times, the relationship between TA and outcome is already evident in the measures performed in the first sessions of the treatment, especially in the third session. ${ }^{30-32}$ The TA increases lineally along the first sessions, suggesting that the patients' involvement in psychotherapy is not only due to their own features, but also emerges in collaboration with some of the psychotherapist's contributions. ${ }^{33,34}$

The used methodology has included the assessment of the TA by patients, psychotherapists or by trained observers. In general, studies ${ }^{21,22}$ have shown that patients assess the TA more consistently than therapists or observers.

\section{Psychotherapy program}

The psychotherapy sector of the Department of Mental Health of the Brotherhood of Santa Casa de Misericórdia of São Paulo is currently composed by three members, all physicians with specialization in psychoanalytical-oriented psychotherapy. Adult patients referred by other sectors of the Department, mainly from the sector of general psychiatry, are seen in a program of brief psychodynamic psychotherapy. Patients referred to psychotherapy had been already followed up by other professionals and had received from their psychiatrists diagnoses according to the clinical descriptions and diagnostic guidelines of the Classification of Mental and Behavioral Disorders of the ICD-10.35

In the psychotherapy sector, patients are screened by one of the three members of the sector, when the indications of psychotherapeutic attention are assessed. After this screening the name of each assessed patient is written into a waiting list to be later called by phone or by mail, in order to begin treatment. As they are patients of the Sistema Unificado de Saúde (Public Health System) the consultations are for free.

All patients included in our study were seen in psychotherapy by resident physicians in their second year of practice in psychiatry or by trainees of the psychotherapy sector. These professionals had few or no previous experience in clinical psychotherapy. The attention was psychoanalytically orientated in a weekly basis along approximately 20 sessions. All professionals involved in the assistance of patients were supervised and participated in theoretical seminars administered by members of the sector.

\section{Objective}

The objective of this study was to assess the impact of the TA on the outcomes of individual brief psychodynamic psychotherapy, measured by a patient version of the California Psychotherapy Alliance Scales (CALPAS-P) in the first sessions.

\section{Methods}

\section{Selection}

We have invited for this study patients ascertained for indi- 
vidual attention in the program of brief psychodynamic psychotherapy of the psychotherapy sector of the Department of Mental Health of the Brotherhood of Santa Casa de Misericórdia of São Paulo.

\section{Instruments}

We used the following instruments in our study:

\section{Questionnaire of sociodemographic data and pre-treatment features}

This questionnaire was composed by the following data: gender, age, skin color, marital status, birth place, schooling, occupational status, family income, expectation about the treatment, previous psychiatric treatment, previous psychotherapeutic treatment, previous admission in psychiatric hospitals, antecedents of suicide attempt, psychiatric diagnosis, family antecedents of psychiatric disorder, presence of a physical disease, clinical treatment concomitant with psychotherapy and use of psychiatric medication during the treatment.

\section{CALPAS-P (Portuguese version)}

The CALPAS-P was the used TA assessment instrument and was the object of a translation and reliability study in its Portuguese version. ${ }^{36}$ CALPAS-P's 24 items are distributed in four subscales: a) Patient's Commitment $(P C)$; b) Patient Working Capacity $(P W C)$; c) Therapist Understanding and Involvement (TUI); d) Working Strategy Consensus (WSC).

\section{Self-reported Questionnaire - SRQ-20}

SRQ-20's twenty items were developed to assess the presence of psychiatric disturbances in the population of developing countries. ${ }^{37,38}$ The Portuguese version of the SRQ-20 ${ }^{39}$ was validated against the Clinical Interview Schedule ${ }^{40}$ in São Paulo. Its internal consistency and reliability were studied by Iacoponi $\& \mathrm{Mari}^{41}$ and the results were comparable to other research questionnaires. $^{42}$

\section{Beck Depression Inventory - BDI}

The Beck Depression Inventory ${ }^{43}$ is probably the most widely used self-reported measure, both in research and clinically. ${ }^{44}$ Its 21 items constitute a self-reported questionnaire, which was developed to assess the presence and intensity of depressive symptoms. The psychometric properties of its Portuguese version have been studied by Gorenstein \& Andrade. ${ }^{45}$

The Hamilton Anxiety Scale ${ }^{46}$ is one of the most used scales in clinical assessment. ${ }^{47}$ It is a scale of hetero-assessment composed by 14 items. The first seven items assess the affective components of anxiety and the remaining, its physiological components.

\section{Procedures}

Before starting psychotherapy, each patient was called for an interview in which the objectives of the study and the procedures involved in his/her participation in the study were explained. All patients gave their informed consent.

Data collection had three steps. In the first one, at the begin- ning of psychotherapy, patients answered to the four assessment instruments: sociodemographic data and pre-treatment characteristics questionnaire, SRQ-20, BDI and Hamilton. These instruments were applied to patients by one of the authors.

The second step involved the assessment with the CALPAS$P$ in the first and third session of psychotherapy. Patients received an envelope with that scale, and answered it, without the presence of their therapists, just after the end of the session, giving it back to a secretary. The envelopes were collected afterwards by one of the authors.

In the last step, performed at the end of psychotherapy, patients were called again by the first author to answer once more to the SRQ-20, BDI and Hamilton. Patients who had dropped out were also called to answer to these instruments.

In our study we considered as the dependent variable the outcome measured by symptomatology change. The main independent variable was the measure of the TA according the CALPAS-P. Sociodemographic data and pre-treatment characteristics were considered as control variables.

\section{Analysis}

The collected data were codified and transcribed into the computational system SPSS (Statistical Package for the Social Sciences) for Windows. ${ }^{49}$ Chi-square test ${ }^{50}$ was used to examine the association between control variables and TA measures with the outcomes in the change of symptoms. Wilcoxon non-parametric test ${ }^{50}$ was used to compare two dependent samples. Mann-Whitney non-parametric test ${ }^{50}$ was used to compare groups of patients with higher and lower TA regarding the change of symptoms. We used $95 \%$ confidence intervals and results were considered significant when $\mathrm{p}$ values were $<.05$.

\section{Results}

\section{Sociodemographic data}

Out of seventy patients who were selected for the program of psychotherapy, sixteen $(22.8 \%$ ) did not participate in the study as eight of them (11.4\%) dropped out and eight (11.4\%) did not give their informed consent to the study. Therefore, the sample was composed by fifty-four patients (77.1\%).

The mean age of subjects was 38.8 years $(\mathrm{SD}=11.3$; ranging from 19 to 62 years), being 41 (75.9\%) females and $13(24.1 \%)$ males. Regarding their marital status, $22(40.7 \%)$ of subjects were single, $15(27.8 \%)$ were married, $7(13 \%)$ were divorced or separated, $6(11.1 \%)$ lived with companions and $4(7.4 \%)$ were widowers. Mean schooling was 10.5 years $(\mathrm{SD}=3.9), 16$ (29.6\%) had finished high-school, $13(24.1 \%)$ had finished college, $8(14.8 \%)$ had some college education, $8(14.8 \%)$ had some primary school, 5 (9.3\%) had some high-school, $3(5.6 \%)$ had finished primary school and $1(1.9 \%)$ was illiterate. Occupational situation showed that 18 subjects $(33.3 \%)$ were wageearners, $13(24.1 \%)$ had domestic activities, $11(20.4 \%)$ were self-employed, $10(18.5 \%)$ did not work and $2(3.7 \%)$ were unemployed. Average family income was R $\$ 1,864.85$-nearly U\$620- $(\mathrm{SD}=1875.42)$. 


\section{Pre-treatment characteristics}

When they started psychotherapy, 26 (48.1\%) patients answered that they were very hopeful with the beginning of the treatment. Regarding previous treatments, $30(55.6 \%)$ subjects had received psychotherapy, $33(66.1 \%)$ had had psychiatric treatment, $6(11.1 \%)$ had been previously hospitalized for psychiatric treatment. Seventeen subjects $(31.5 \%)$ had already attempted suicide. Twenty-eight (51.9\%) subjects had a family history of psychiatric disorders, 21 (38.9\%) had a physical disease, and $15(27.8 \%)$ were being followed up by other specialists. Forty-three patients $(79.6 \%)$ were using psychiatric medication during psychotherapy.

\section{Psychiatric diagnoses}

Regarding psychiatric diagnoses, 32 (59.3\%) subjects received the diagnostic hypothesis of depressive disorder, 8 $(14.8 \%)$, recurrent depressive disorder, $3(5.6 \%)$, persistent mood disorder, 1 (1.9\%), bipolar affective disorder, 4 (7.4\%) anxiety disorders, $1(1.9 \%)$, phobic anxiety disorder, $1(1.9 \%)$, schizophrenia, 1 (1.9\%) unspecified psychosis, 1 (1.9\%), reaction to severe stress, 1 (1.9\%) dissociative disorder, and 1 (1.9\%) personality disorder.

\section{Psychotherapy outcomes}

Fifty-four patients answered to the three symptom-assessment scales before starting psychotherapy and $50(92.6 \%)$ answered to the same scales at the end of the study. For the SRQ20 , the median score at the beginning was 13 (minimum = zero; maximum $=20$ ) and at the end was 11.5 (minimum = zero; maximum $=20$ ). The assessment of the distribution of these two groups showed a significant statistical difference between them ( Wilcoxon test $p<.01$ ). For the BDI, at the beginning of psychotherapy, the obtained median was 24 (minimum = zero; maximum $=64$ ) and at the end, it was 22 (minimum = zero; maximum $=50$. We also found a statistically significant change between the initial and final punctuation (Wilcoxon test $p=.034$ ). For the Hamilton scale, at the beginning the median was 30 ( minimum $=2$; maximum $=53$ ) and at the end, it was 24.5 points ( minimum $=3$; maximum $=48$ ). The initial and final punctuation was also statistically different (Wilcoxon test $p<.01$ ). These results are in Table 1.

\section{Psychotherapy: more and less favorable outcomes}

We measured the difference between the punctuation obtained at the beginning and at the end of psychotherapy for each of the assessment instruments. The difference with a positive value represented the group with more favorable outcomes and values equal to zero or negative represented

Table 1 - Symptoms scales: initial and final means.

\begin{tabular}{lccc}
\hline Scales & Initial & Finel & $\mathrm{p}^{*}$ \\
\hline SRQ-20 & 13 & 11,5 & $<.01$ \\
BDI & 24 & 22 & .034 \\
Hamilton & 30 & 24,5 & $<.01$ \\
\hline Note: SRQ-20: Self-reported Questionnaire; BDI: Beck Depression Inventory; Hamilton: \\
$\begin{array}{l}\text { Hamilton Anxiety Scale. } \\
\text { *Wilcoxon non-parametric test }\end{array}$
\end{tabular}

the group of patients with the less favorable psychotherapy outcomes.

\section{Measures of the therapeutic alliance}

The following measures were obtained at the first and at the third sessions of psychotherapy; the mean and the standard deviation of the four subscales and of the total of the CALPASP. At the first session, $\mathrm{PC}$ mean was 5.7 ( $\mathrm{S} D=.6$ ), $\mathrm{PWC}$ mean, 4.6 ( $\mathrm{S} D=.88)$, TUI mean, 6.1 ( $\mathrm{S} D=.6$ ), WSC mean, $5.9(\mathrm{~S} D=.7)$ and for the total score, the found mean was $5.6(\mathrm{~S} D=.5)$. At the third session PC mean was 5.9 ( $\mathrm{S} D=.6)$, PWC mean, 4.8 $(\mathrm{S} D=1)$, TUI mean, $6.2(\mathrm{~S} D=.6)$, WSC mean, $6.1(\mathrm{~S} D=.7)$ and for the total score, the found mean was $5.8(\mathrm{~S} D=.6)$.

The comparison between the CALPAS-P total at the first and the third session showed that there was a statistically significant difference (Wilcoxon test $p<.01$ ).

\section{CALPAS-P: high and low therapeutic alliance}

In order to assess which groups of patients had produced the highest and the lowest levels of TA, the mean of total scores and of the four subscales of the CALPAS-P at the first and the third sessions was divided into four groups. The criterion used for this division was the values of percentiles 25,50 and 75 of the mean of punctuation of the CALPAS-P and of the subscales.

Based on this division into four groups we selected the group of patients with a higher level of alliance and grouped the remaining patients in other group (Table 2).

Study on the impact of control variables over psychotherapy outcomes

Sociodemographic data and pre-treatment characteristics of subjects of the sample were not statistically different, comparing groups of patients with more or less favorable outcomes (chi-square test $\mathrm{p}>.05$ ). Some of these data can be observed in Table 3.

Table 2 - Distribution of means of the CALPAS-P from the first and third session in two groups.

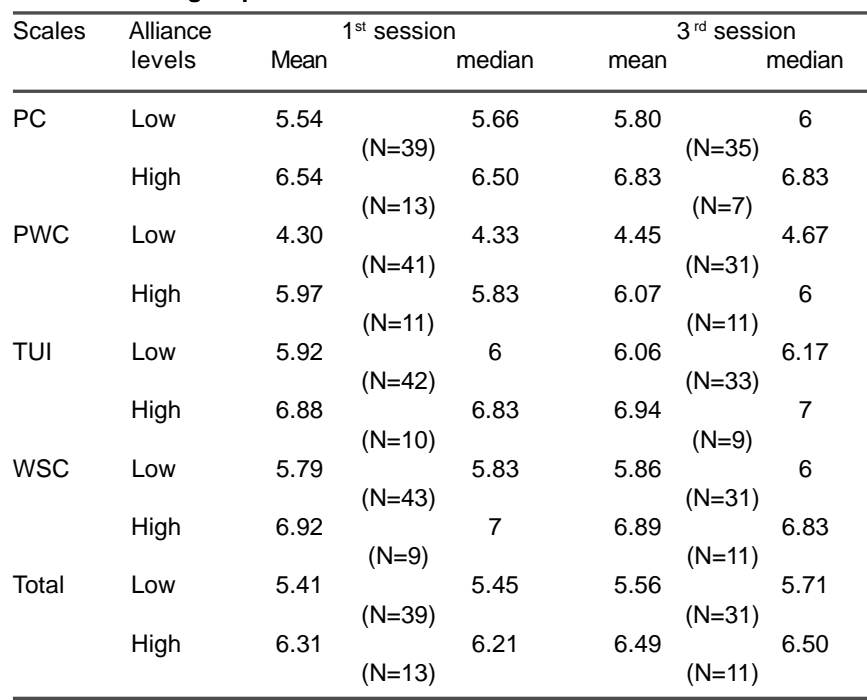

Note: $P C=$ Patient Commitment; $P W C=$ Patient Working Capacity; $T U I=$ Therapist Understanding and Involvement; $W S C=$ Working Strategy Consensus; Total = total score . 
Table 3 - Impact of control variables on psychotherapy's outcomes.

\begin{tabular}{lccc}
\hline & $\begin{array}{c}\text { SRQ-20 } \\
\mathrm{p}^{*}\end{array}$ & $\begin{array}{c}\text { BDI } \\
\mathrm{p}^{*}\end{array}$ & $\begin{array}{c}\text { Hamilton } \\
\mathrm{p}^{*}\end{array}$ \\
\hline Gender & .28 & .64 & .09 \\
Age & .41 & .08 & .56 \\
Schooling & .86 & .67 & .75 \\
Month family income & .32 & .33 & .88 \\
Medication during psychotherapy & .85 & .91 & .48 \\
\hline
\end{tabular}

Note: SRQ-20: Self-reported Questionnaire; BDI: Beck Depression Inventory; Hamilton: Hamilton Anxiety Scale.

${ }^{*}$ Chi-square test.

\section{Study on the impact of the therapeutic alliance over psychotherapy outcomes}

First, we selected a group of patients who had the highest alliance punctuation and another group of patients who had the lowest alliance punctuation. In the first session we found that the TUI punctuation distributed in these two groups showed a statistically significant difference (Mann-Whitney test $p=.040$ ) regarding psychotherapy outcomes obtained by the BDI. For the other subscales and the total score of the CALPAS-P no statistically significant difference was found.

In the third session we found a statistically significant difference between the PWC punctuation in these two groups (Mann-Whitney test) regarding the BDI $(p=.031)$ and the Hamilton $(p=.020)$. We also found a statistically significant

Table 4 - Impact of high and low levels of therapeutic alliance on the outcomes.

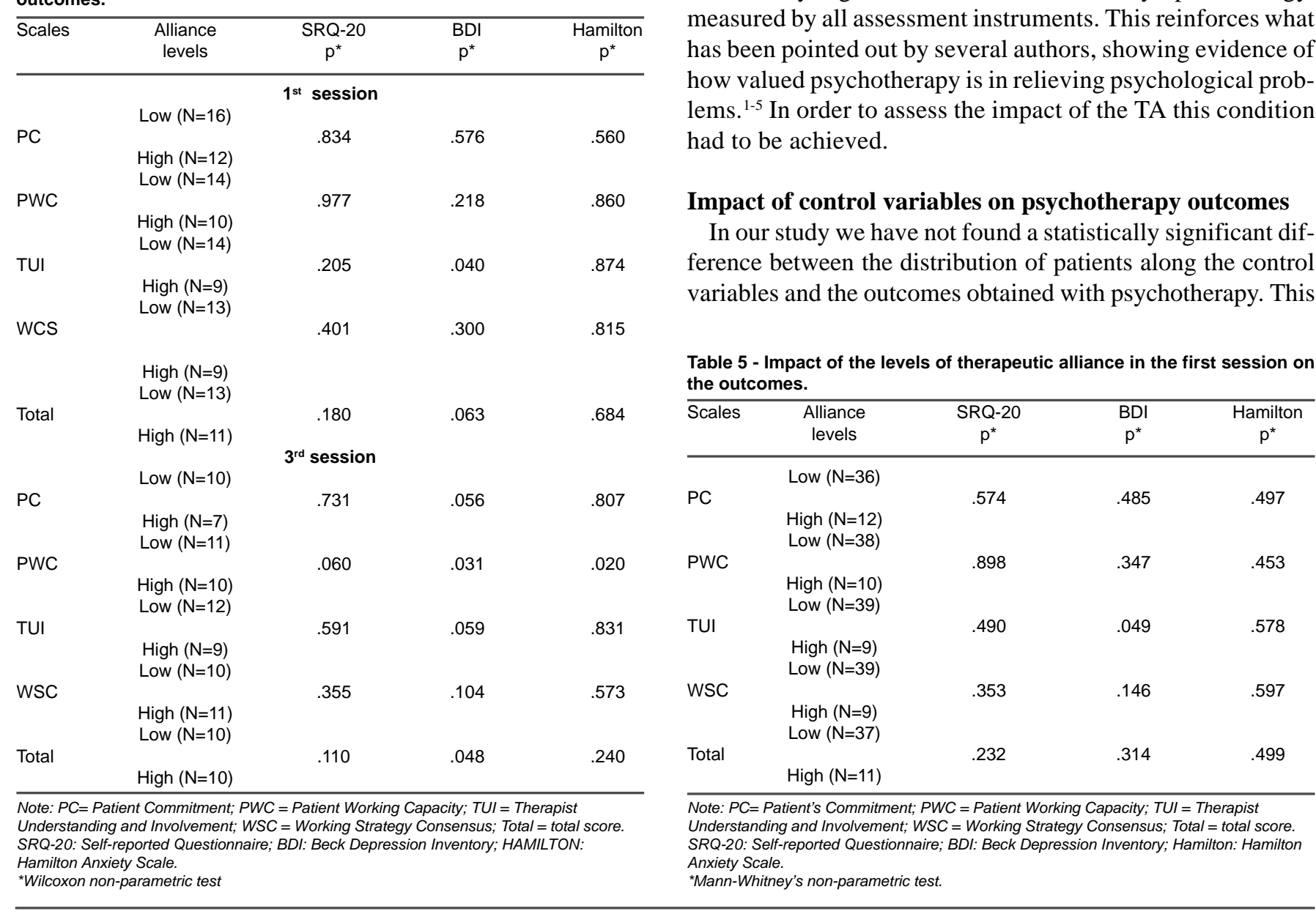

difference (Mann-Whitney test $p=.048$ ) between the total CALPAS-P punctuation, regarding psychotherapy outcomes obtained by the BDI. For the other subscales and for the total of the CALPAS-P there was no statistically significant outcome. These outcomes are in Table 4.

Next, we selected a group of patients who had the highest TA means and gathered the remaining patients in one single group. In the first session we found a significant statistical difference between the TUI punctuation of the group of patients with the highest TA punctuation and the remaining patients, regarding psychotherapy outcomes measured by the BDI (Mann-Whitney test $p=.049$ ). These results are in Table 5.

In the third session, we found a statistically significant difference in the PWC punctuation of the groups of patients with the highest TA punctuation, (Mann-Whitney test), compared to the remaining patients, regarding psychotherapy outcomes measured by the SRQ-20 ( $p=.017)$, by the BDI $(p=.022)$ and by the Hamilton $(p=.023)$. These results can be observed in Table 6 and Figure.

\section{Discussion}

\section{Psychotherapy outcomes}

The aim of this study was to examine the impact of the TA in a program of brief psychodynamic psychotherapy. Patients who were submitted to this type of intervention showed a statistically significant reduction in the symptomatology, measured by all assessment instruments. This reinforces what rers, showing evidence of ms. ${ }^{1-5}$ In order to assess the impact of the TA this condition

\section{pact of control variables on psychotherapy outcomes}

In our study we have not found a statistically significant difference between the distribution of patients along the control variables and the outcomes obtained with psychotherapy. This

\section{the outcomes.} Anxiety Scale.
Understanding and Involvement; $W S C=$ Working Strategy Consensus; Total = total score 
Table 6 - Impact of the levels of therapeutic alliance in the third session on the outcomes.

\begin{tabular}{|c|c|c|c|c|}
\hline Scales & $\begin{array}{l}\text { Alliance } \\
\text { levels }\end{array}$ & $\begin{array}{c}\text { SRQ-20 } \\
\mathrm{p}^{*}\end{array}$ & $\begin{array}{c}\mathrm{BDI} \\
\mathrm{p}^{*}\end{array}$ & $\begin{array}{c}\text { Hamilton } \\
\mathrm{p}^{*}\end{array}$ \\
\hline & Low (N=34) & & & \\
\hline PC & $\begin{array}{l}\operatorname{High}(\mathrm{N}=7) \\
\operatorname{Low}(\mathrm{N}=31)\end{array}$ & .794 & .074 & .488 \\
\hline PWC & $\begin{array}{l}\text { High }(\mathrm{N}=10) \\
\text { Low }(\mathrm{N}=32)\end{array}$ & .017 & .022 & .023 \\
\hline TUI & $\begin{array}{l}\text { High }(\mathrm{N}=9) \\
\text { Low }(\mathrm{N}=30)\end{array}$ & .590 & .058 & .647 \\
\hline WSC & $\begin{array}{l}\text { High }(\mathrm{N}=11) \\
\text { Low }(\mathrm{N}=31)\end{array}$ & .391 & .108 & .825 \\
\hline Total & High $(\mathrm{N}=10)$ & .306 & .114 & .301 \\
\hline
\end{tabular}

finding may support the hypothesis that the reduction in the symptomatology was not correlated to the patients' sociodemographic and pre-treatment characteristics.

\section{Impact of the therapeutic alliance on psychotherapy outcomes}

Patients who had higher alliance levels, measured by the TUI in the first session, had more favorable BDI outcomes. The TUI is a subscale of the CALPAS-P which was developed to assess the patients' perception about the therapist's capability of understanding their point of view and suffering during psychotherapy. It assesses the therapist's capability of showing patients they are committed in helping them to overcome their problems. The instrument used for the assessment of the TA was based on how patients see the alliance. Therefore, the association between a higher punctuation in the TUI and BDI outcomes already found at the first session seems to indicate that patients who identified in their therapists a higher capability of understanding and involvement in their issues had a higher reduction in their depressive symptoms.

Some researchers have explored how the variables which involve the therapist increase or prevent the development of a favorable and positive alliance. ${ }^{51,52}$ This may be related to the way in which patients perceive their own therapists. According to Rogers ${ }^{53}$ the conditions offered by the therapist should suffice to trigger a healing process, suggesting that the relationship provided by the therapist is the main responsible for the treatment's effectiveness. Some studies supported the hypothesis that a good therapeutic relationship was correlated to a positive outcome. ${ }^{54,55}$ However, the subjective assessment of the relationship performed by the patient was responsible for the highest impact on psychotherapy outcomes, rather than the therapist's actual behavior. The impact of the psychotherapy outcomes did not rely on the objective measure of the level of empathy, coherence or on an unconditional sympathy of the therapist for the patient: the measure of the patient's perception was the best predictive factor of success of the helping

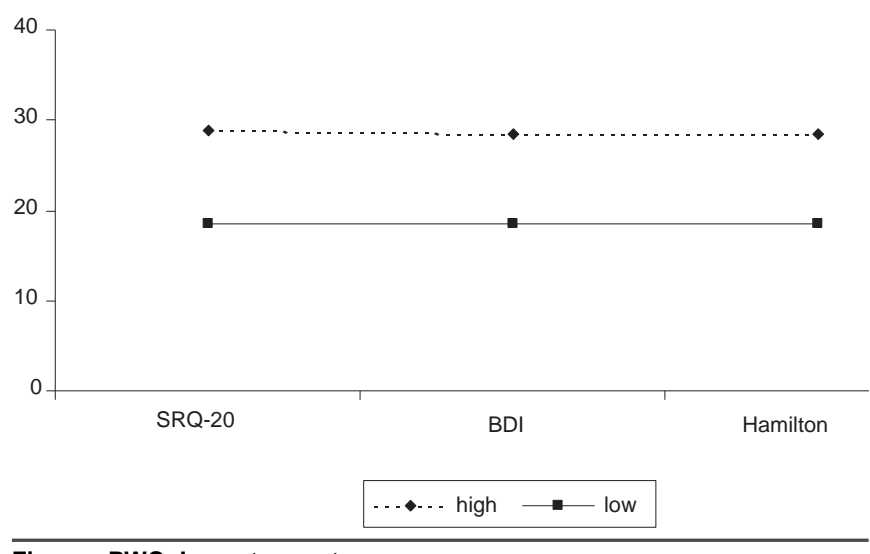

Figure - PWC: Impact on outcomes.

process. ${ }^{56,57}$ In that study, the perception that patients had about the capability of understanding and involvement of their therapists, measured by the TUI, was associated to a greater impact on the change of depressive symptoms.

The change associated with the BDI may be justified by the higher number of patients with depressive disorder in this sample $(81.6 \%)$. One hypothesis is that for the group of depressed patients the perception that there was a higher involvement and understanding of their therapists resulted in a greater benefit as measured by the BDI.

With data from the third session, patients with higher capability for the work alliance, measured by the PWC, showed the most favorable outcomes as assessed by all scales. According to the authors of the CALPAS-P ${ }^{58}$ the PWC is a subscale that aims at measuring the patient's working capability. It assesses the patients' capability of observing their reactions, of working actively with the therapist's remarks and to solve problems. According to this concept a higher capability of patients to establish the working alliance has produced the most significant outcomes in this study, what has been already observed by other authors ${ }^{59}$ who reported a significant correlation between the working alliance (PWC) and the improvement in the symptomatology.

For Sterba ${ }^{60}$ the working alliance arises from the functioning of patients with a more mature ego and from the therapist's interventions, what may indicate that patients with higher measures of the PWC had a more integrated ego and were more able to link themselves to the therapists' interventions and, due to that, to obtain better outcomes.

The higher impact of the PWC on psychotherapy outcomes could be related to the modality of psychotherapy employed in this study. One study performed by Marmar, ${ }^{31}$ although using a previous version of the CALPAS-P, found that the PWC punctuation was related to the outcomes presented by the group submitted to brief dynamic psychotherapy. According to these authors, the higher impact of the PWC could be justified as the psychodynamic approach would demand a greater contribution of patients to settle their problems. It seems thus that patients with a more integrated ego had better conditions to establish a working alliance with their therapists and to contrib- 
ute to the propositions made by this modality of psychotherapy.

The lack of association between the other subscales of the CALPAS-P with psychotherapy outcomes could be related to the structure of the scale, developed to encompass a wide range of dimensions of the alliance. As the four subscales were moderately correlated, ${ }^{36,61}$ that dimension might have been the most related with the sample of patients involved in this study.

Furthermore, this sample was heterogeneously constituted, what may have increased the dispersion of responses. A last aspect may be related to the therapists' inexperience, what could have hampered a clear establishment of the objectives and tasks of psychotherapy. The WSC is the CALPAS-P's subscale to assess the degree of consensus between patient and therapist regarding the strategy and tasks of psychotherapy. In this study we did not find an association between the punctuation of this subscale and psychotherapy outcomes. Besides, the approach proposed by psychodynamic-oriented psychotherapies gives less emphasis to these aspects of the treatment.

\section{Limitations of the study}

Due to their professional formation, the supervisors were not used to conduct brief psychotherapies, what could have caused some discrepancy between the supervisors' conception regarding the process of change in psychotherapy and the proposed criteria for a brief psychodynamic psychotherapy. For example, there could have been some differences in the way of approaching issues regarding the end of psychotherapy. This is a limitation that has been observed by other authors, ${ }^{62}$ who have stated that much of the research in psychotherapy demonstrating the importance of the TA has been based on a context of protocols involving brief psychotherapies, although the TA was not systematically thought for this modality of psychotherapy. Besides, there were no attempts to clarify differences in the type of alliance needed to conduct brief psychotherapies.

We also have not used a technical manual that could have provided a more uniform pattern to the procedures. Defending the use of manuals in psychotherapy, some authors ${ }^{63}$ state that they propitiate an initial basis to make the psychotherapy operative in a more competent way. Luborski ${ }^{64}$ argues that a good alliance favors therapists to adhere to the use of a manual, as therapists who are capable of establishing a good alliance may keep closer to the planning of that psychotherapy and because a good alliance allows therapists to work according to the intended technique. On the other hand, the adherence of therapists to manuals is only one of the aspects indicating the extension of the therapist's competence. For Luborski ${ }^{64}$ the greatest agent for an effective psychotherapy is the therapist's personality, particularly in creating conditions to form an affective and supportive relationship with the patient.

The inexperience of therapists may have contributed with an important bias regarding psychotherapy outcomes. For example, the interventions could have been directed to supportive aspects, rather than to achieve the transferential situation, preventing certain questions to be focused during the psychotherapeutic process, contributing for the appearance of resistances and a weakening of the TA.
As a rule, studies suggest that there is no clear relationship between the therapists' experience and psychotherapies outcomes. ${ }^{6,65}$ However, there are indications that more experienced therapists are capable of deviating from recommended techniques when dealing with more difficult patients and that inexperienced therapists are more accessible to suggestions regarding their technique and style. Appropriate levels of personal adjustment and clinical sensitivity are also essential, besides the therapists' characteristics. The exam of the role performed by the therapists' interventions in the development of the alliance is an important investigating pathway.

Other limitations may be related to the sample. Patients referred to psychotherapy were already being treated with their psychiatrists. This study has not assessed the conditions in which the referral had been performed and how these conditions could have influenced, for example, the patient's motivation. The demand for psychotherapy could have occurred rather as a response to a suggestion of their physician, without any further reflection. Besides, patients waited until being called to begin psychotherapy, and this waiting period could have interfered in the issues that generated the referral.

Patients have not directly met criteria for indication to brief psychodynamic psychotherapy. Our study has also not assessed other pre-treatment characteristics that could have shown an association between the alliance and the outcomes, such as the capability of establishing good interpersonal relationships. For Safran \& Muran, ${ }^{62}$ due to the limitation of the time of the brief therapy, the selection of patients is particularly important.

Regarding the patients' schooling, although the mean schooling of the sample could be deemed high, some of the subjects had a very low schooling. As the reliability study of the Portuguese version of the CALPAS-P ${ }^{36}$ was performed in a sample of university graduate subjects, an effort to validate the scale in other populations could show different outcomes.

Regarding psychotherapy's outcomes, this study has not used a control group for comparison. Perhaps the most important suggestion for further discussion would be whether the improvement found in the symptomatology was obtained by a spontaneous remission. This study has used a sample of patients with different diagnoses, varying in severity and duration. Furthermore, we have not assessed the maintenance of changes in the symptomatology after the end of psychotherapy.

This study has also not used other perspectives to assess outcomes, such as changes in conflict patterns, general functioning and objectal relationship. Furthermore it has not compared the impact of the TA in other psychotherapies, as the TA may have an important role in psychodynamic psychotherapy but not in other modalities.

A last point to be discussed is the exam of the relationship between TA, outcomes and improvement of symptoms at the first sessions. The main and most important hypothesis indicates that a positive alliance that appeared in the first sessions is associated to an improvement in the symptomatology. This study has shown that high levels of working alliance were associated to the best outcomes. However, it is possible that patients who had already improved in the 
first sessions had a trend to consider more positively their therapists and psychotherapy. In this study, we did not assess how the change in symptoms occurred after being assessed the TA and the role of these first changes on the subsequent outcome.

\section{Conclusions}

Patients who were submitted to the program of brief psychodynamic psychotherapy had a statistically significant decrease in their symptomatology, measured by all assessment instruments.

Control variables had not a statistically significant impact on psychotherapy outcomes.

The association between the Therapist Understanding and Involvement (TUI) in the first session and the Beck Depressive Inventory (BDI) seems to indicate that patients who re- ported having perceived that their therapists had a greater capability of understanding and involvement in their issues had a higher decrease in depressive symptoms.

The measures of impact of the TA, obtained in the third session, showed that patients with higher levels in the Patient Working Capacity (PWC) showed the most favorable psychotherapy outcomes as measured in all the scales that assessed symptomatology changes.

\section{Acknowledgements}

To professors Sidney Blatt, Rainer Krause and Peter Fonagy for making comments about the study during the $5^{\text {th }}$ Annual Training Program in Research on Psychoanalysis promoted by the International Psychoanalytical Association and by the London University in August 1999.

\section{References}

1. Stiles WB, Shapiro D, Elliot R. Are all psychotherapies equivalent? Amer Psychol 1986;41:165-80.

2. Ivanoff A, Blythe BJ, Briar S. The empirical clinical practice debate. Social Casework 1987;68:290-8.

3. Luborsky L. Research can now affect clinical practice: a happy turnaround. Clin Psychol 1987;40:56-60

4. Lambert MJ, Bergin AE. The effectiveness of psychotherapy. In: Bergin AE, Garfield SL, eds. $4^{\text {th }}$ ed. Handbook of psychotherapy and behavioral change. New York: John Wiley; 1994. p. 143-89.

5. Roth A, Fonagy P. What works for whom? A critical review of psychotherapy research. New York: Guilford Press; 1996. p. 350-2.

6. Smith ML, Glass GV. Meta-analysis of psychotherapy outcome studies. Am Psychol 1977;32:752-60.

7. Videka-Sherman L. Meta-analysis of research in social work practices in mental health. Social Work 1988;33:325-37.

8. Luborsky L, Singer B, Luborsky L. Comparative studies of psychotherapy; Is it true that everybody has won and all must have prizes? Arch Gen Psychiatry 1975;32:995-1008.

9. Gaston L. The concept of the alliance and its role in psychotherapy: theoretical and empirical considerations. Psychotherapy 1990;27:143-53.

10. Horvath AO, Gaston L, Luborsky L. The therapeutic alliance and its measures. In: Nancy Miller et al. Psychodynamic treatment research: a handbook for clinical practice. New York: Basic Books; 1993. p. 247-73.

11. Marziali E, Alexander L. The power of the therapeutic relationship. Amer J Orthopsychiat 1991;61(3):383-91.

12. Freud S. A dinâmica da transferência (1912). In: Edição Standard Brasileira das Obras Completas. Vol. 12. Rio de Janeiro: Imago; 1976. p. 131-43.

13. Zetzel ER. Current concepts of transference. Int J Psychoanal 1956;37:369-76.

14. Greenson RR. The working alliance and the transference neuroses. Psychoanal Q 1965;34:155-81.

15. Bordin ES. The generalizability of the psychoanalytic concept of working alliance. Psychother Theor Res Pract 1979;16:252-60.

16. Luborsky L. Helping alliances in psychotherapy. In: Cleghhorn JL, ed. Successful psychotherapy. New York: Brunner/ Mazel; 1976. p. 92-116.

17. Safran JD, Muran JC. The resolution of ruptures in the therapeutic alliance. J Consult Clin Psychol 1996;64(3):447-58.

18. Krupnick JL, Sotsky S, Simmens S, Moyer J, Elkin I, Watkins J, Pilkonis P. The role of therapeutic alliance in psychotherapy and pharmacotherapy outcome: findings in the National Institute of Mental Health Treatment of Depression Collaborative Research Program. J Consult Clin Psychol 1996;64:532-9.

19. Wolfe BE, Goldfried MR. Research on psychotherapy integration: recommendations and conclusions from the NIMH workshop. J Consult Clin Psychol 1988;56:448-51.

20. Henry WP, Strupp HH, Schacht TE, Gaston L. Psychodynamic approaches. In: Bergin AE, Garfield SL, eds. $4^{\text {th }}$ ed. Handbook of psychotherapy and behavior change. New York: John Wiley; 1994. p. 467-508.

21. Horvath AO, Symonds BD. Relation between working alliance and outcome in psychotherapy: a meta-analysis. J Couns Psychol 1991;38:139-49.

22. Martin JD, Garske JP, Davis K. Relation of the therapeutic alliance with outcome and other variables: a meta-analytic review. J Consult Clin Psychol 2000;68(3):438-50.

23. Frieswyk SH, Allen JG, Colson DB, Coyne L, Gabbard GO, Horwitz L, Newsom G. Therapeutic alliance: its place as process and outcome variable in dynamic psychotherapy research. J Consult Clin Psychol 1986;1:32-9.

24. Hatcher RL, Barends A. Patient's view of the alliance in psychotherapy: exploratory factor analysis of three alliance measures. J Consult Clin Psychol 1996;64:1326-36.

25. Safran JD, Wallner LK. The relative predictive validity of two therapeutic alliances measures in cognitive therapy. Psychol Assess J Consult Clin Psychol 1991;3:188-95.

26. Tichenor V, Hill CE. A comparison of six measures of the working alliance. Psychother Res Pract 1989;26:195-9.

27. Barrett-Lennard GT. Dimensions of therapist response as causal factors in therapeutic personality change. Psychol Monogr 1962;76(562).

28. Gomes-Schwartz B. Effective ingredients in psychotherapy: prediction of outcome from process variables. J Consult Clin Psychol 1978;46:1023-5.

29. Hartley D, Strupp HH. The therapeutic alliance: its relationships to outcome in brief psychotherapy. In: Masling J, ed. Empirical studies of psychoanalytic theories. Hillsdale: Lawrence Erlbaum; 1983. Vol.1. p. 1-38.

30. Horvath AO. The therapeutic relationship: from transference to alliance. J Clin Psychol 2000;56(2):163-73.

31. Marmar CR, Gaston L, Thompson LW, Gallaguer D. Alliance and outcome in late-life depression. J Nerv Ment Dis 1989;177:464-72.

32. DeRubeis R, Feely M. Determinants of change in cognitive therapy for depression. Cogn Ther Res 1991;14:469-82.

33. O'Malley S, Suh D, Strupp HH. The Vanderbilt psychotherapy process scale: a report on scale development and a process-outcome study. J Consult Clin Psychol 1983;51:581-6.

34. Moras K, Strupp HH. Pre-therapy interpersonal relations, client alliance and outcome in brief psychotherapy. Arch Gen Psychiatry 1982;39:405-9. 
35. Organização Mundial de Saúde (Coordenação). Classificação de transtornos mentais e de comportamento da CID-10: descrições clínicas e diretrizes diagnósticas. Porto Alegre: Artes Médicas; 1993.

36. Marcolino JAM, Iacoponi E. Escala de aliança psicoterápica da Califórnia na versão do paciente. Rev Bras Psiquiatr 2001;23(2):88-95.

37. Harding TW, deArango MV, Baltazar J, Climent C, Ibrahim HA, LadridoInacio LL, Murthy RS, Wig NN. Mental Disorders in primary health care: a study of their frequency and diagnosis in four developing countries. Psychol Med 1980;10:231-41.

38. Harding TW, Climent C, Diop M, Giel R, Ibrahim HA, Murthy RS, Suleiman MA, Wig NN. The WHO collaborative study on strategies for extending mental health care: the development of new research methods. Am J Psychiatry 1983;140:1474-80.

39. Mari JJ, Williams P. A validity study of a psychiatric screening questionnaire (SRQ-20) in primary care in the city of São Paulo. Br J Psychiatry 1986;148:23-6.

40. Goldberg DP, Cooper B, Eastwood MR, Kedward HB, Shepherd M. A standardized psychiatric interview for use in community surveys. Br J Prev Soc Med 1970;24:18-23.

41. Iacoponi E, Mari JJ. Reliability and factor structure of the Portuguese version of the Self-Reporting Questionnaire. Int J Soc Psychiatry 1989;35:213-22.

42. Goldberg DP, Willians P. The User's guide to the General Health Questionnaire. Windsor: NFER/Nelson; 1988.

43. Beck AT, Ward CH, Mendelson M, Mock J, Erbaugh J. An inventory for measuring depression. Arch Gen Psychiatry 1961;41:561-71.

44. Dunn G, Shan P, Hand D. Statistics and the nature of depression. Psychol Med 1993;23:871-89.

45. Gorenstein C, Andrade L. Inventário de depressão de Beck: propriedades psicométricas da versão em português. Rev Psiq Clin 1998;25(5 Ed Especial):245-50.

46. Hamilton M. The assessment of anxiety states by rating. Br J Medical Psychol 1959;32:50-5.

47. Keedwell P, Snath RP. What do anxiety scales measures? Acta Psychiatr Scand 1996;93:177-80.

48. Crits-Christoph P, Siqueland L, Blaine J, Frank A, Luborsky L, Onken LS et al. Psychosocial treatments for cocaine dependence: results of the National Institute on Drug Abuse Collaborative Cocaine Treatment Study. Arch Gen Psychiatry 1999;56:493-502.

49. Norusis MJ. SPSS for Windows. Professional Statistics. Release 6.0. Chicago; 1993.

50. Siegel, J. Estatística não paramétrica. Editora Mc Graw Hill do Brasil; 1981.

51. Foreman SA, Marmar CR. Therapist actions that address initially poor therapeutic alliances in psychotherapy. Am J Psychiatry 1985;142:922-6.

52. Kokotovic AM, Tracey TJ. Working alliance in the early phase of counseling. J Couns Psychol 1990;37:16-21.
53. Rogers CR. Client-centered therapy. Cambridge: Riverside Press; 1951.

54. Rogers CR, Gendlin GT, Kiesler DV, Truax LB. The therapeutic relationship and its impact: a study of psychotherapy with schizophrenics. Madison: University of Wisconsin Press; 1967.

55. Barrett-Lennard GT. The helping relationship: crisis and advance in theory and research. Couns Psychol 1985;13:278-94.

56. Mitchell KM, Bozart JD, Krauft CC. Reappraisal of the therapeutic effectiveness of accurate empathy, non-possessive warmth and genuineness. In: Gurman AS, Razin AM, eds. Effective psychotherapy. New York: Pergamon Press; 1977. p. 482-502.

57. Orlinsky D, Howard K. The psychological interior of psychotherapy: exploration with the therapy session reports. In: Greenberg LS, Pinsof WM, ed, The psychotherapeutic process: a research handbook. New York: Guilford Press; 1986. p. 477-500.

58. Gaston L, Marmar CR. Manual of California Psychotherapy Alliance Scales - CALPAS. Manuscrito não publicado. McGill University and University of California; 1991.

59. Marmar CR, Weiss DS, Gaston L. Toward validation of the California therapeutic alliance rating system. Psychol Assess 1989;1:46-52.

60. Sterba RF. The fate of the ego in analytic therapy. Int J Psychoanal 1934;115:117-26.

61. Gaston L. Reliability and criterion-related validity of the California Psychotherapy Alliance Scales - patient version. J Consult Clin Psychol 1991;3:68-74.

62. Safran JD, Muran JC. The therapeutic alliance in brief psychotherapy. Washington (DC): American Psychological Association; 1998.

63. Strupp HH, Binder JL. Psychotherapy in a new key: a guide to time-limited dynamic psychotherapy. New York: Basic Books; 1984.

64. Luborsky L, McLelan AT, Woody GE, O'Brien CP, Auerback A. Therapist success and it determinants. Arch Gen Psychiatry 1985;42:602-11.

65. Bergin AE. The evaluation of therapeutic outcomes. In: Bergin AE, Garfield SL, eds. Handbook of psychotherapy and behavior change. New York: Wiley; 1971.

\section{Correspondence:}

José Alvaro Marques Marcolino

Departamento de Saúde Mental da Santa Casa de São Paulo

Rua Major Maragliano, 241

04017-030 São Paulo, SP, Brazil

Tel.: (0xx11) 5087-7005

E-mail: alvaromarcolino@uol.com.br 